\title{
Parte VI
}

\section{DE PALAVRAS E DE VIAJANTES ITALIANOS}





\title{
A história latino-americana recontada por italianos na época do fascismo
}

\author{
Latin American history as recounted by \\ Italians at the time of fascism
}

Carla Brandalise*

\begin{abstract}
Resumo: Através de uma perspectiva epistemológica e metodológica específica, os usos políticos do passado, este artigo visa analisar a particular narrativa histórica que a Itália produz na época do fascismo a propósito de sua ligação com a América Latina, em especial, nos anos de 1920. É nesta década que o interesse pelo subcontinente sul-americano aparece com especial força, em meio a uma perspectiva de elevação de prestígio, de disputa de mercados econômicos e anseios de presença da 'nova' Itália na região. Aproveitando, inclusive, a produção italiana do passado liberal e de finais do século XIX, faz-se uma reelaborarão e uma recontextualização discursiva na forma de um elenco cognitivo da intrínseca e 'natural' relação entre as nações latinas em seu todo. Proposição essa que se encaixa como instrumento mítico-simbólico de integração através de um passado idealizado, muitas vezes, fictício como uma miragem.
\end{abstract}

Palavras-chaves: Usos políticos do passado. Nacionalismo. Fascismo.

Abstract: Through a specific epistemological and methodological perspective, the political uses of the past, this paper aims to analyze the particular historic narrative which Italy produces at the time of fascism, with regard to its link to Latin America, particularly during the 1920's. It's during this decade that he interest for the south-american subcontinent makes itself particularly noticeable, amid a perspective of an increase in prestige, of the dispute for new economic

\footnotetext{
* Graduada em Licenciatura, Bacharelado em História e mestrado em Ciência Política pela Universidade Federal do Rio Grande do Sul. Doutorou-se em História Política pelo

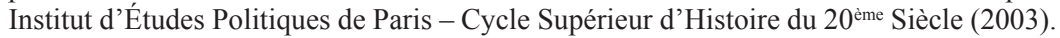
Atualmente é professora adjunta de História Moderna e Contemporânea na UFRGS; professora permanente nos Programas de Pós-Graduação em História e em Relações Internacionais - UFRGS.
} 
markets and expectations of presence of the 'new' Italy in the region. Taking advantage, also, of Italian production from the liberal past and from the end of the XIX century, this paper aims at a discourse reworking and recontextualization in the form of a cognitive index of the intrinsic and 'natural' relationship between the Latin American nations as a whole, a proposition which fits as a mythicsymbolic of integration through an idealized past, which is often as fictitious as a mirage.

Keywords: Political uses of the past. Nationalism. Fascism.

Na reflexão que deu origem a já clássica obra, Les usages politiques $d u$ passé, publicada em 2001, os organizadores François Hartog e Jacques Revel, ao afirmarem que todo o discurso histórico é susceptível de permear certa utilização política, apontam alguns casos em que tal procedimento têm especial lugar. Citam justamente o dos estados nacionais em busca de legitimação através da reformulação de seu passado $^{1}$ :

O alcance tanto historiográfico quanto público da deformação da história por motivos nacionais: a necessidade, por exemplo, de construir uma imagem da nação que seja coerente, gratificante, enraizada... voltada ao futuro... a partir da mobilização de recursos oferecidos pelo passado (Hartog, 2001, p. 09).

Esta perspectiva epistemológica e metodológica, os usos políticos do passado, se aplica muito bem na análise da narrativa histórica que a Itália produz na época do fascismo a propósito de sua ligação com a América Latina, em especial, nos anos de 1920. Aproveitando, inclusive, a produção italiana do passado liberal e de finais do século XIX, faz-se uma reelaborarão e uma recontextualização discursiva na forma de um elenco cognitivo. Proposição essa que se encaixa como instrumento mítico-simbólico de natural integração através de um passado idealizado, muitas vezes, fictício como uma miragem.

Mas, nesse caso, é preciso descartar a ideia de simples manipulação. Em tal reconstrução narrativa não é evidente até onde iria qualquer

\footnotetext{
1 "Certains genres ont, plus que d'autres, mobilisé un ou plusieurs de ces usages, et ils nous en donnent les exemples les plus visibles. L'histoire nationale est, par excellence, l'un d'eux." (HARTOG, 2001, p. 14).
} 
malversação historiográfica ou gradações de crença evidente nessa idealização. É bem provável que tais indivíduos envolvidos na composição dessas exposições acreditassem em boa parte de sua redação, como acontece quando há uma submersão ou impregnação em um escopo ideológico ou em uma real motivação nacionalista. Como coloca Benedict Anderson, em Comunidades Imaginadas, ao criticar Ernest Gellner:

\begin{abstract}
Algo ferozmente, Gellner [...] estabelece que 'o nacionalismo não é o despertar das nações para a autoconsciência: ele inventa nações onde elas não existem'. O inconveniente desta formulação, contudo, é que Gellner está tão ansioso em demonstrar que o nacionalismo se dissimula sob falsas aparências, que assimila 'invenção' a contrafação e falsidade, ao invés de assimilá-la a 'imaginação' e 'criação' (Anderson, 1989, p. 14). ${ }^{2}$
\end{abstract}

Ao buscar reescrever seu destino na longa duração através de relatos apologéticos de fundação, a Itália, durante o fascismo, em se tratando da América Latina, trabalhou com a ideia de Primato, sob uma continuidade biológica. Uma concepção de origens comuns que materializava as reivindicações de privilégio da Itália no subcontinente latino em nome da matriz formadora, Roma, apresentada como a 'mãe da latinidade'. Consistia em estabelecer vinculações etéreas e eternas de comunidade. Mas qual era o interesse da Itália neste esforço?

Após a marcha sobre Roma, as perspectivas de uma maior expansão comercial e o desejo de exercer uma acrescida influência sobre os destinos político-culturais da América Latina tornaram-se um dos eixos de referência das relações exteriores do governo fascista italiano. ${ }^{3} \mathrm{Na}$ primeira fase do regime, a política internacional da Itália ainda não havia optado por uma via predominantemente colonialista, que a levaria a olhar novamente com cobiça para a África, em detrimento do sul das Américas, enquanto alvo de interesses imediatos possíveis. Ao contrário,

2 Ou ainda, segundo Alessandro Campi (Nación. BA: Nueva Visión, p. 136), ao se referir ao fervor criativo que forjaram o 'surgimento' das nações: “[...] difícilmente pueda reducirse a una gigantesca operación de migromancia o a una forma de manipulación de las mentes inspirada por políticos para asegurarse el control social sobre los ciudadanos de los respectivos Estados. 'Construir' la nación... no es lo mismo que 'inventarla' totalmente.

3 Ver Brandalise (2005, 602 p.). 
a expectativa de forçar uma nova posição mundial para a Itália, um dos objetivos, aliás, da tomada do poder, levara os dirigentes italianos a conjeturar justamente a porção sul do continente americano como uma parcela do planeta ainda não totalmente saturada pela concorrência de outras potências.

Afinal de contas, essa região era plenamente contemplada pelos seus emigrados, o que poderia retratar uma vantagem, se desta vez, e contrariando as práticas dos governos italianos anteriores, fosse com presteza redimensionada. Os anseios, porém, iam muito além da exploração do 'recurso humano italiano' sob lugar, isto é, não se tratava apenas de promover uma reaproximação com os seus emigrados partidos e, assim, esperar, por contabilidade, o aumento do grau de influência nos assuntos latino-americanos. A legião de emigrados deveria, sem dúvida, exercer seu 'papel histórico', assumindo a posição de associados, representantes, consumidores, difusores, intermediários políticos e culturais de sua pátria de origem ou descendência. Porém, a promoção da exuberância italiana exigia ambições muito maiores. Tratava-se, antes de tudo, de fomentar ligações político-econômicas com as elites crioulas através da noção de pertencimento comum, na concepção de que todos compunham a mesma raça latina. Essa era uma forte ideia na intencionalidade do fascismo.

Ora, a 'nova Itália', na perspectiva de seus dirigentes e aderentes, estaria destinada a ser no mundo moderno aquilo que o Império Romano fora no passado. Nada menos que uma 'civilização grandiosa'. Como outrora, a vanguarda da humanidade. Através do discurso de recuperação da latinità perdida, pretendia-se criar a comunhão com todos os latinos, com todo o 'povo latino' sul-americano. Em termos metafóricos, era preciso reunir os vínculos da latinidade sob o conceito originário de romanità e sua posterior transformação em italianità. Comungar dessa herança endógena partilhada e da qual a Itália representaria a fonte, a essência originária. Associava-se latinità, romanità e italianità, sob os desígnios teóricos e práticos do fascismo, o único julgado apto e competente a finalmente dirigir essa verdadeira ressurreição. No entanto, não se almejava necessariamente a imposição forçada desse regime em tais terras distantes. Antes, fomentar as relações econômicas, políticas e culturais. Abrir mercados para a Itália, inclusive no domínio da cultura.

Pretendia-se, de fato, tocar a imaginação recuperando o esplendor 'romano' ligado a um passado heróico, cujo continente latino-americano 
teria sido, em seu devido momento histórico, um dos campos de exercício. Afinal, argumenta-se, essas terras foram contempladas com a participação ativa de italianos desde a chegada primeira dos europeus, desde o 'alvorecer' dos tempos dessa América, dita, latina.

A Itália sob o fascismo aspirava nada mais do que reescrever a própria história latino-americana segundo suas interpretações, onde, por exemplo, a figura do próprio Cristóvão Colombo aparece como o começo de tudo, o marco fundador. Pretendia-se tecer um cenário de legendas, ao mesmo tempo épicas e visionárias, estóicas e inesquecíveis. Na concepção de pertencimento a uma mesma linhagem, era imperioso provar e, sobretudo, ver reconhecido o papel imprescindível e insubstituível do povo italiano, 'romano', na formação originária da América Latina.

Para cumprir essas perspectivas, um esforço prático e intelectual é lançado pelo regime. Há um incentivo para que venha à tona um interesse pelo subcontinente. Corroborado, em especial, pelos simpatizantes do regime. Mas não só. Em maior ou menor grau de engajamento, comentaristas, estudiosos e curiosos se colocam a refletir e a investigar a América Latina. Viajantes são enviados para conhecer e relatar o continente. ${ }^{4}$ Dentro deste espírito, surgem livros ${ }^{5}$ e revistas. ${ }^{6}$

4 Segundo Federico Finchelstein (2010. p. 147), “durante los primeros años del fascismo, en especial durante la década de 1920, algunos de los viajeros fascistas que cruzaban el Atlántico tenían la misión de arraigar y consolidar los designios de Mussolini para Argentina y América Latina... El primer movimiento para 'la acción intelectual y espiritual fascista' fue 'exportación' de intelectuales partidarios del régimen que debían establecer un contacto directo con la 'vida y la conciencia' de países latinos."

5 Entre as inúmeras obras publicadas, especialmente, na década de 1920, boa parte por institutos financiados pelo regime, aparecem: BLAIS, Valeria. Nicaragua; BORGHI, Giulio. Colombia; GALLEGARI, G.V. Messico; CUMIN, Gustavo. Il Perù; LANTINI, Pietro. Guatemala; MORI, Mario. San Domingo; MORINI, Armando. Venezuela; NINNI, Alessandro. Chile; QUARTA, Oronzo. Costa Rica; RICCARDI, Ricardo. Equador. Ver relação em Colombo, fasc.V, set. 1927. p. 256-257.

6 Diretamente ligada ao Regime encontra-se a Revista Colombo, vinculada ao Istituto Cristoforo Colombo. Outras revistas, com gradações variadas de adesão ao regime fascista, eram: Rivista d'Italia e d'America; Le Vie d'Italia e dell'America Latina. Esse último periódico é fundado pelo Touring Club Italien de Milão em janeiro de 1924, sendo publicada até 1932. Em editorial, o periódico se congratula pelas palavras de apoio e incentivo recebidas da parte do Rei e de Benedito Mussolini. Entre seus objetivos, "valorizar o trabalho dos italianos, a influência e os grandes progressos realizados através dos nossos compatriotas nos estados sul-americanos" (Franzoni, 1924, p. 269-277). Já a Rivista circula entre os anos de 1923 a 1930, com a intenção de "levar aos cantos mais distantes a palavra da Itália de hoje, que trabalha na disciplina e na ordem para consolidar sua economia e política e sua afirmação e expansão no mundo" (Rivista d'Italia e d'America, n. 3, mar. 1926. p. 358). Ver também: VANGELISTA, Chiara. Uma revista italiana e a emigração no Brasil durante os primeiros anos do Fascismo: Le Vie d'Italia e dell'America Latina, 1924-1932. In: Veritas, v. 40, n. 159, 1995. 
As impressões, descrições, análises feitas por italianos residentes ou seus descendentes, por representantes diplomáticos ou comerciais, por jornalistas são aproveitadas. ${ }^{7}$ Funda-se, na Itália, o Istituto Cristoforo Colombo para agregar todas essas iniciativas e propagar as intenções do regime em se inserir mais solidamente em terras latino-americanas. A revista Colombo será seu órgão de imprensa oficial. A propósito das atividades do Instituto, Luigi Bacci anunciava:

Sua fundação constitui um dever de italianità; ele irá encorajar uma cooperação eficaz para que a civilização latina não seja considerada como uma simples expressão de retórica; antes, seja percebida como uma grande força de expansão, colocada a serviço dos interesses que a Itália já possui e pretende desenvolver com mais vigor...Entre a Itália e todos esses países, não subsiste nenhum desacordo, não existe e nem pode existir nenhuma desconfiança. ${ }^{8}$

Tommaso Mancini, por ocasião do cruzeiro-mercante, Nave Italia, enviado à América Latina pelo regime fascista em 1924ㅇ, em um dos primeiros esforços de promoção político-comercial entre as partes,

7 De acordo com Angelo Trento (Os viajantes italianos na América Latina durante o período fascista: entre curiosidade e ideologia. In: Locus: revista de história, Juiz de Fora, v. 14, n. 2, 2008. p. 106) "Nos vinte anos, entre as duas guerras, registrou-se na Itália um interesse pela América Latina... Muitas das temáticas em questão foram abordadas também aproveitando-se tanto de nomes relevantes quanto de autores iniciantes e que se valeu muito mais, se comparada ao passado, da categoria dos jornalistas, que percorreram com certa freqüência, as Américas."

8 O Instituto começa suas atividades em março de 1924, apresentando-se como um estabelecimento voltado à difusão de um "programa orgânico, síntese do pensamento dos países diretamente concernidos" BACCI, Luigi. L'attività dell'Istituto Cristoforo Colombo. In: Colombo, fasc.V, set. 1927. p. 223. Ver: Brandalise, 2005, p. 31-46.

9 Em relação à passagem do cruzeiro pela Argentina, Emilio Gentile (L'emigrazione italiana in Argentina nella politica di espansione del nazionalismo e del fascismo. In: Storia Contemporanea, ano XVII, n.3, jun. 1986, p. 379) escreve: "Desde os primeiros tempos que se seguiram a sua conquista do poder, o fascismo manifestou um interesse especial pela Argentina [...] Mas, a primeira aproximação importante e direta do problema da emigração e da italianità na Argentina teve lugar durante o cruzeiro da Nave Italia na América do Sul." Sobre o cruzeiro da Nave Italia pela América Latina, ver entre outros: GIURIATI, Giovanni. Tradizioni di italianità nell'America latina. In: Colombo, fasc. I, juin 1926; GIURIATI, G. La Crociera Italiana nell'America Latina. Relazione di S. E. Giovanni Giuriati dinnanzi a S. M. il Re. Roma: Istituto Coloniale, 1925; La grande fiera campionaria navigante nell'America Latina. In: Le Vie d'Italia e dell'America Latina, n. 3, março 1924, p. 383-384; MISEROCCHI, Manlio. L'America Latina attraverso il mio oblò. Pistoia: Grazzini, 1925; BRACCHIGLIONE, Ettore e CARMINATI, Aldo (ed.) Il Cile e gli Italiani del Cile: omaggio alla crociera italiana nell' América Latina. Valparaiso: Camera italiana di commercio, junho 1924; CARRARA, Enrico. Turim: Giani, 1925; Camera italiana di Comercio ed arti di San Paolo del Brasile. Relazione presentata alla Crociera della R. Nave 'Italia'. São Paulo: Rossetti \& Rocco,1924. 
já anuncia os objetivos italianos decorrentes de seus 'direitos inalienáveis':

Atingir e conservar um lugar de primeira ordem sobre o continente fecundado por milhões de nossos filhos, sobre a terra povoada por uma margem tão ampla de seus descendentes. Valorizar as forças e as energias existentes, para a conquista de um lugar que só a Itália tem direito. Não existe nenhum outro país que tanto deu à América que a Itália - do grande genovês e de Vespúcio até os milhões de seus tenazes colonizadores. É um direito... (Mancini, 1924, p. 16).

$\mathrm{Na}$ formulação dos relatos procuram-se o triunfalismo, os gestos espetaculares, a grandiloquência, a hagiografia. Encontram-se os nomes que a história reteve e outros por ela esquecidos, em uma campanha metódica, povoando-a de mitos. Efetua-se um recenseamento de personagens e fatos susceptíveis de glorificação, sob formas hiperbólicas, superdimensionadas, irrealistas na maior parte das vezes. A Itália declara querer se lançar em uma "cruzada de amizade" no Novo Mundo, justificada pela grandeza da sua presença ultramar e na certeza de recuperar a autoestima perdida em meio a um ambiente muitas vezes hostil ou preconceituoso: "Após a maravilhosa conquista realizada em cada domínio pelo povo italiano, pioneiro em civilização, quem ousa chamar de indesejáveis os italianos, quem ousa os olhar com desprezo?"10

Antes de tudo, glorificam-se os 'heróis anônimos', a exemplo dos ligurianos, "a vocês que, seguindo a nobre e gloriosa tradição de seus antepassados, asseguraram a árdua via marítima para levar em terras americanas, o gênio e a força de nossa linhagem, a vocês que, enfrentando cada dificuldade, souberam afirmar o respeito do nome da Madre Patria" (Colombo, fasc. I, 1926, p. 07). Em meio às narrativas aparece justamente este tom ao mesmo tempo dramático e espetacular, ao se intencionar retratar uma grande e pacífica aventura humana.

Para os cronistas, podia-se observar a presença digna e brava de italianos ao longo de toda a história da América Latina. Afinal, concebiam, tal parcela do planeta devia o seu próprio surgimento e existência a um italiano. Figura essa que estaria na origem de tudo. Sem ele nada seria possível, o subcontinente emergeria à luz. As trombetas das quatro virtudes cardiais vão ressonar para honrar tal personagem especial. Aquele edificado como o símbolo mesmo da indissolubilidade

${ }^{10}$ Giudizi americani sull'emigrante italiano. In: Corriere Italiano, n. 47, 23 nov. 1924, p. 02. 
dos laços latinos sob égide italiana. O perfeito herói Cristovão Colombo, o descobridor.

Os italianos estariam, igualmente, na vaga de independências das nações latino-americanas. Teriam lutado contra os tiranos em favor da liberdade. Continuariam lá no período pós-independências, contribuindo sobremaneira na elaboração da consciência nacional e na construção material desses países. Junto aos heróis anônimos agrega-se, e esta é a ambição maior, os grandes vultos, os homens destacados, quando não legendários, os protagonistas da história, os mesmos que, em geral, não teriam tido o devido reconhecimento, deliberam os cronistas: "Ao grande liguriano navegador, Colombo, glória da Itália. Todos os acordes da florescente civilização além-mar celebrarão o grande italiano e imortalizarão sua história." (Silvagni, 1927)

A definitiva mitificação do navegador exigia o estabelecimento de uma imagem pessoal adequada ao seu papel. Colombo passa a ser alguém dotado de uma imaginação prodigiosa e de uma vontade perseverante que, através de sua descoberta, permitiu a passagem decisiva da hipótese à realidade manifesta. Um espírito valoroso que influenciou os destinos do mundo ao desestruturar as fronteiras geográficas e mentais de uma Europa ainda medieval. Um ser alegórico que personifica a transcrição de uma ideia abstrata em materialidade. Descortinam-se assim as facetas dessa personalidade, cujos feitos não são menos do que a própria invenção de um Mundo Novo. A carga onírica de sua viagem torna-se emblemática do fabuloso. E porque não? Chega-se ao ponto de sugerir a santificação do navegador. Para a revista Le Vie d'Italie et dell'America Latina, "a proposição de santificar Colombo não é nova (ela existia desde 1892), mas esse objetivo foi esquecido. Nos últimos tempos, um certo número de pessoas recolocou em discussão o assunto. É questão de recomeçar a campanha junto a Santa-Sé."11

O pantéon igualmente contempla Américo Vespúcio, pois não se podia esquecer esse outro italiano que explorou o Novo Mundo na esteira de Cristovão Colombo. Prova de sua importância incomensurável, fora ele que deixara seu nome ao continente americano. "Colombo criou os primeiros vínculos que Vespúcio assegurou para sempre, ligando o nome da Itália e de Roma aos anúncios da civilização americana", sublinha o professor da Universidade de Palermo, Alberto Magnaghi, em sua obra I Grandi Pioneri Italici: Amerigo Vespucci, editada em Roma pelo Istituto Cristoforo Colombo, em 1924.

${ }^{11}$ Le Vie d'Italia e dell'America, n. 3, mar. 1926, p. 358. 
O professor ensina, aliás, que o território da bacia do Prata, antes mesmo de ser conhecido, fora desenhado em uma carta geográfica porque Vespúcio supunha a sua existência e havia feito menção em sua terceira viagem. Logo, fora um italiano que, em espírito, descobrira primeiramente este lugar, afirmava Magnaghi. Esse último ainda se perguntava se os italianos que residiam no Rio de Janeiro sabiam que a cidade assim se nomeava porque Vespúcio ali aportara em $1^{\circ}$ de janeiro de 1502, no curso de sua segunda viagem. Ao mesmo tempo, pedia justiça a Vespúcio, dado que ele divisara o rio Amazonas, precedendo em cinco ou seus meses o espanhol Vincente Pinzón (Magnaghi, 1924, p. 49-50).

A Enciclopedia Italiana Treccani, por sua vez, vai realizar esforços para restituir a honra de Vespúcio e "destruir a odiosa lenda de altercação e de inimizade" entre os "dois heróis da Descoberta", que fazia de Vespúcio um usurpador dos méritos de Colombo. Como prova do contrário, apresenta-se a carta que Colombo enviara a seu filho Diogo, pouco antes de sua morte, na qual enuncia julgamentos favoráveis sobre Vespúcio. A depreciação desse último teria sido obra, sobretudo, segundo a Enciclopedia, de historiadores espanhóis e portugueses. ${ }^{12}$

Os cronistas tenderam a sistematizar e organizar suas versões da história da "incalculável contribuição dos italianos" à América Latina em três grandes fases. Assim, a primeira fase seria justamente a do período colonial, época dos navegadores e desbravadores intrépidos, que procuravam o imprevisto, o não habitual, curiosos que eram em desencadear as travessias de ultramar e as explorações continentais.

A segunda fase estaria na primeira metade do século XIX, tempos de formação das nacionalidades latino-americanas e que, da mesma forma, correspondia ao Risorgimento italiano. Essa etapa contemplaria o grande momento dos "patriotas", homens que imaginavam e lutavam por um mundo de liberdade, não submetido a autoridades arbitrárias e tirânicas. Constituíam os defensores das causas justas, os que haviam

12 Verbete: Cristoforo Colombo. In: Enciclopedia Italiana di scienze, lettere ed arti. Istituto dell'Enciclopedia Italiana. p. 810. Sobre a obra, também conhecida como Enciclopedia Italiana Treccani, o historiador Gioacchino Volpe, coloca: "Venuta al mondo in un momento che il mondo guardava con molto interesse l'Italia, l'Enciclopedia è andata incontro a questo interesse, lo ha alimentato, ha fatto la sua parte per attirar il mondo verso l'Italia" O Istituto responsável pela formulação da obra foi fundado em fevereiro de 1925 e tinha como diretor científico Giovanni Gentile. Grande parte dos demais participantes da empreitada era aderente do Manifesto degli intellettuali fascisti (1925). Ver: MASTROGREGORI, Massimo. Sulla 'collaborazione' degli storici italiani durante il fascismo. In: Belfagor, n. 2, 2006, p. 151-168. 
escapado da perseguição na Itália e se refugiado no além-mar, lá agindo pelo bem civil das nações de acolhida.

Enfim, a terceira fase, aquela dos estados nacionais já consolidados tanto de um lado, a própria Itália, quando do outro, os países latinoamericanos. Marcaria o período da segunda metade do século XIX e inícios do XX, época do dilúvio emigratório, dos heróis anônimos obrigados a abandonar sua Itália por necessidade econômica, atingindo as costas americanas. Italianos que criaram por todos os lugares, pequenas 'Itálias'.

Para o período colonial elevam-se ao patamar, além de Colombo e Vespúcio, vários outros personagens, como o veneziano Sebastiano Caboto. Aprende-se que, a despeito da presença anterior espanhola, o verdadeiro explorador do sistema hidrográfico do Prata teria sido Caboto, através da sua expedição ocorrida entre 1526 e 1530. Certo, admitiam os italianos, mesmo que sob os auspícios da coroa espanhola. O escritor Giuseppe Pavanello vai contar a saga do navegador na obra Sebastiano Caboto alla scoperta del Paranà e del Paraguay. Descreve que "pela ação do navegador italiano, a Espanha acrescentou uma pérola nova e resplandecente à sua Coroa, ao mesmo tempo que a ciência esclarece uma porção do desconhecido."13

Na revista Le Vie d'Italia e dell'America Latina, Enrico Pietro Molinatti trata, por sua vez, de restabelecer o que seria a trajetória de seus concidadãos no Peru desde a primeira exploração do país:

Se os italianos, através de seu glorioso pioneiro Cristoforo Colombo, ocupam um lugar preeminente na história da América Latina, eles também aparecem na história do Peru, onde outros luminosos representantes da etnia figuraram e ocuparam um lugar notável na aurora da conquista espanhola (Molinatti, 1926, p. 1140-1147).

Os ancestrais Giovanni Battista Pastene e Pedro Valdivia podem, prossegue Molinatti, ser classificados entre os conquistadores mais próximos do descobridor do Peru, o espanhol Francisco Pizzaro. Em companhia desse último, Pastene, - "capitão de terra, homem político hábil, empreendedor e ilibado, que no meio de um mundo de

13 Texto publicado em Le Vie d'Italia e dell'America Latina, n. 3, março 1926, p. 303-311. As referências ao navegador veneziano são numerosas, como no artigo de Giacomo Pavoni (Il lavoro nell' Argentina coi primi emigranti. In: Le Vie d'Italia e dell'America Latina, n. 2, fev. 1926, p. 142-146): "Em 1527, alguns séculos antes, a imigração italiana teve um mensageiro na Argentina, Sebastiano Caboto, o primeiro navegador a percorrer a Bacia do Prata". 
aventureiros, muito frequentemente gananciosos, sabia se distinguir pelo mérito de seu caráter e de sua honestidade" - teria sabido exercer um papel crucial na submissão do Peru. E Valdivia, de seu lado, sob demanda de Pizzaro, conduzira com sucesso a conquista.

Na segunda fase - primeira metade do século XIX - no momento das emancipações, encontrar-se-iam personagens da etnia que teriam feito pender a balança pela liberdade e libertação. Um exemplo estava no descendente de italianos, nascido em Buenos Aires, em 1770, o general Emanuele Belgrano, o "herói da independência argentina." Em 1927, Alfredo Oliverio assim o descreve “... Belgrano representa a profunda identidade de nossos sentimentos e de nossos ideias... marca a união espiritual entre Argentina e Itália” (Oliverio, 1927, p. 330).

Até mesmo Simon Bolívar, nesse esforço narrativo, foi associado ao espectro italiano. B. Maineri afirma que o libertador americano concebera seus objetivos e desejos na Itália: "Bolívar jurou solenemente lutar com todas as suas forças para libertar a América do jugo espanhol na cidade eterna, aos pés da colina sagrada, a Colle dell'Aventino". O autor faz alusão à suposta influência, sobre o comportamento de Bolívar, da viagem que o sul-americano fizera à Itália, em 1805, com a idade de 22 anos: "Roma contribuiu, ainda que de maneira indireta, a dar a liberdade e independência a estas nações que logo se desenvolveram neste continente descoberto pelo Genovês Imortal" (Maineri, 1927, p. 54-56).

Um símbolo máximo, na comemoração dos 'patriotas', aparecia em Giuseppe Garibaldi, mas não só. Como coloca Luigi Manzi, “a verdade é que as insurreições políticas, que se sucederam quase periodicamente na Itália, levaram ao exílio no Prata um forte contingente de patriotas, em geral, homens de valor tanto pela inteligência, como pelo coração." E completa "a epopeia dos primeiros exilados que honraram a pátria distante com a inteligência, a virtude da coragem e o valor da espada, a qual usaram para a libertação da América Latina não é suficientemente conhecida pelos italianos"14 (Manzi, 1924, p. 662).

O escritor Mario Puccini fala igualmente sobre a participação italiana na emancipação política das nações latino-americanas:

Um fato é certo: as repúblicas da América tiveram, em maior ou menor grau, contato com nossa civilização e elas derivam muito de nós. O povo italiano, que sempre foi um povo inclinado à emigração, por sua obra vigorosa indubitavelmente cooperou ao

${ }_{14}$ Ver ainda: Manzi, (1925. p. 29-31). 
bem estar das nações nascentes [...] e impulsionou nessas regiões, uma consciência autônoma que fez nascer um movimento clássico de busca de independência (Puccini, 1925, p. 65).

Quanto a Garibaldi, o próprio Mussolini lhe outorga homenagem por ocasião das comemorações de sua morte, "de 1830 a 1870, o nome e os altos feitos de Garibaldi preencheram a história da América e da Itália" (Buti, 1932, p. 762). Vários são os artigos redigidos a propósito da presença do "herói dos dois mundos" no sul latino-americano. Ulderico Tegani esboça:

[...] nessa enorme região, nós encontramos os traços, as memórias, as testemunhas da estada e da obra de nosso magnífico cavaleiro do ideal, deste grande embaixador da italianidade que, durante tempos obscuros, fez brilhar sob a luz da glória, a imagem da Patria nostra e, com seus esplêndidos feitos, reafirmou o prestígio de nossa linhagem (Tegani, 1932, p. 1114).

Sobre o engajamento do grupo liderado por Garibaldi, no Uruguai, em apoio a Rivera na guerra civil contra Manuel Oribes, esse último sustentado pelo ditador argentino Rosas, Lucio Ambruzzi conta que o 'herói' organizara a Legião italiana, financiada pelos ligurianos que lá habitavam:

Eles não eram numerosos os italianos no Uruguai, cerca de 800. Mas eles se sentiram suficientemente fortes para formar uma Legião de 500 homens e ajudar a expulsar o invasor. Garibaldi era o chefe. E foi nesse momento que nasceu a camicia rossa, símbolo da glória garibaldina, que o herói trará à Itália, já consagrada pela vitória. ${ }^{15}$

O segundo período fora especial não apenas por contar com a emigração do tipo risorgimentale, mas também pela chegada dos primeiros 'burgueses empreendedores' e de diversos profissionais liberais, engenheiros, artistas, pesquisadores, professores. Aqui é descrito um festival de criações e intervenções italianas na América. No domínio artístico, os italianos teriam promovido o refinamento, desde

15 AMBRUZZI, Lucio.L'Uruguay. In: Colombo, fasc. XX, set./out. 1929. p. 404. Ainda no artigo Giuseppe Garibaldi, da Enciclopedia Italiana Treccani (tomo XVI, p. 390-394, 1932), é esboçada a participação do italiano na Guerra dos Farrapos no Rio Grande do Sul, "seguiram-se anos de aventura romanesca e de heroísmo corajoso [...] Garibaldi assume o comando da pequena frota de guerra da digna República". 
o fim do século XVIII, dos gostos e difundido o senso estético, o amor à beleza e ao pitoresco nesse continente.

Para a Rivista d'Italia e d'America, a afinidade com as belas artes seria, aliás, "um dom particular da raça". Uma prova estaria em Giovanni Picazzari, que procedera, em 25 de maio de 1813, a primeira execução pública do hino nacional argentino. Ainda, Picazzari, junto com Virgilio Rabaglio, havia fundado em Buenos Aires, no ano de 1822, a Sociedad Filarmonica e a Academia de Musica y Canto. A partir dessa cidade, "centro do mundo teatral latino-americano", a influência artística dos italianos se estendera a todos os grandes centros urbanos próximos, como Montevidéu e Santiago. ${ }^{16}$

No campo técnico o aporte fora extraordinário. Os italianos estariam na base do sucesso industrial dos países latino-americanos: "Todos os estudiosos da economia argentina reconhecem voluntariamente que a imigração italiana deu um impulso maior ao desenvolvimento desse país." Recai, por exemplo, ao engenheiro Carlo Peregrini a criação, em Buenos Aires, da escola Politécnica, bem como aos italianos são imputados os mais importantes projetos arquitetônicos dessa capital (L'Opera degli Italiani in Argentina, 1924, p. 670).

Para a terceira fase, a que se retraça a partir da segunda metade século XIX, o período da emigração de camponeses e trabalhadores, seria urgente a recuperação da dignidade e do devido reconhecimento. Este fluxo populacional vindo da Itália teria significado uma verdadeira providência à América Latina. Ulderico Tegani vem em auxílio ao expor a importância desses italianos na formação da Argentina:

Fala-se da pobreza, da ignorância de nossos emigrados, no entanto, ninguém pode negar as virtudes do coração: as que os fez ternos com suas famílias e inclinados ao trabalho. Ninguém pode negar que recaem sobre eles os méritos do ensino prático de uma vida honesta e trabalhadora, bem como os passos em direção a uma era de tranquilidade, de bem-estar e de cultura desse país, que, até recentemente, era, em grande parte, semibárbaro (Tegani, 1924, p. 197).

Assim, frente ao fatos invocados, que demonstrariam os trabalho de criação, de fundação e de consolidação do subcontinente latinoamericano, esses cronistas italianos defendiam a ideia de que a Itália teria um direito de inserção legítimo e histórico. Em reforço, expõe-se

${ }_{16}$ L'Opera degli Italiani in Argentina. In: Rivista d'Italia e d'America, n. XI-XII, dez. 1924, p. 670-675. 
a natural vinculação da raça, onde a Pátria Mãe da latininidade, a Itália, mereceria um papel de destaque. Algo que não lhes seria devidamente reconhecido. A concepção, nesse ensaio de reconstrução da história da América Latina, era evidenciar através de relatos, crônicas, biografias a considerada decisiva participação italiana desde suas origens até o presente. Em geral, fazia-se alusão a essa Itália agora regida pelo regime restaurador do prestígio merecido, o fascismo.

\section{Referências}

AMBRUZZI, Lucio. L'Uruguay. In: Colombo, fasc. XX, p. 404, set./out. 1929.

AMBRUZZI, Lucio. Giuseppe Garibaldi. In: Enciclopedia Italiana Treccani (tomo XVI, p. 390-394, 1932).

ANDERSON, Benedict. Nação e consciência nacional. São Paulo: Ática, 1989.

BACCI, Luigi. L'attività dell'Istituto Cristoforo Colombo. In: Colombo, fasc. V, p. 223, set. 1927.

BRACCHIGLIONE, Ettore; CARMINATI, Aldo (ed.). Il Cile e gli Italiani del Cile: omaggio alla crociera italiana nell' América Latina. Valparaiso: Camera italiana di commercio, jun. 1924.

BRANDALISE, Carla. Les rapports internationaux de l'Italie envers l'Amérique latine: 1922-1936. Lille: ANRT, 2005.

BUTI, Antonio Bandini. Anita Garibaldi: un gentile vincolo tra l'Italia e il Brasile. In: Le Vie d'Italia e dell'America Latina, n. 7, jul. 1932.

CARRARA, Enrico. Turim: Giani, 1925; Camera italiana di Comercio ed arti di San Paolo del Brasile. Relazione presentata alla Crociera della R. Nave 'Italia'. São Paulo: Rossetti \& Rocco, 1924.

Colombo, fasc. I, p. 07, 1926.

FINCHELSTEIN, Federico. Fascismo trasatlántico: ideología, violencia y sacralidad en Argentina y en Italia. 1919-1945. Buenos Aires: FCE, 2010.

FRANZONI, Ausonio. Italia ed America Latina. In: La vie d'Italia e dell'America Latina, n. 3, p. 269-277, mar. 1924.

GENTILE, Emilio. L'emigrazione italiana in Argentina nella politica di espansione del nazionalismo e del fascismo. In: Storia Contemporanea, ano XVII, n. 3, p. 379, jun. 1986.

Giovanni Giuriati dinnanzi a S. M. il Re. Roma: Istituto Coloniale, 1925.

Giudizi americani sull'emigrante italiano. In: Corriere Italiano, n. 47, p. 02, 23 nov. 1924.

GIURIATI, Giovanni. La Crociera Italiana nell'America Latina. Relazione di S. E.

GIURIATI, Giovanni. Tradizioni di italianità nell'America latina. In: Colombo, fasc. I, juin 1926.

HARTOG, François; REVEL, Jacques. Notes de conjocture historiographique. In: Les usages politiques du passé. Paris: Éditions de l'EHESS, 2001. 
La grande fiera campionaria navigante nell'America Latina. In: Le Vie d'Italia e dell'America Latina, n. 3, mar. 1924.

Il lavoro nell' Argentina coi primi emigranti. In: Le Vie d'Italia e dell'America Latina, n. 2, p. 142-146, fev. 1926.

L'Opera degli Italiani in Argentina. In: Rivista d'Italia e d'America, n. XI-XII, p. 670675, dez. 1924.

Le Vie d'Italia e dell'America Latina, n. 3, p. 303-311; 358, mar. 1926.

MAGNAGHI, Alberto. I Grandi Pionieri Italici: Amerigo Vespucci. Roma: Istituto Cristoforo Colombo, 1924. p. 49-50.

MAINERI,B. Roma e l'indipendenza dell'America latina. In: Colombo, fasc. I, p. 54-56, jan. 1927.

MANCINI,Tommaso. Problemi e mezzi della nostra penetrazione economica nell' America Latina. Santiago: Comitato pro crociera R. Nave Italia, 1924.

MANZI, Luigi. La spedizione della Legione Italiana di Montevideo per la prima guerra d'Independenza. In: Rivista d'Italia e d'America, n. XIII-XIV, p. 29-31, jan./fev. 1925.

MANZI, Luigi. L'epopea italiana nell'America Latina. In: Rivista d'Italia e d'America, n. XI-XII, nov./dez. 1924.

MASTROGREGORI, Massimo. Sulla 'collaborazione' degli storici italiani durante il fascismo. In: Belfagor, n. 2, p. 151-168, 2006.

MISEROCCHI, Manlio. L'America Latina attraverso il mio oblò. Pistoia: Grazzini, 1925.

MOLINATTI, Enrico Pietro. Gl'italiani nel Perù. In: Le Vie d'Italia e dell'America Latina, n. 10, p. 1140-1147, oct. 1926.

OLIVERIO, Alfredo. In: Colombo, fasc. VI, out. 1927.

PUCCINI, Mario. La nuova e la vecchia America. In: Rivista d'Italia e d'America, ano III, dez. 1925.

SILVAGNI, G. Cristoforo Colombo et la scoperta dell'America. In: Colombo, fasc. VI, oct. 1927.

TEGANI, Ulderico. Garibaldi nel Rio Grande do Sul. In: Le Vie d'Italia e dell'America Latina, n. 10, out. 1932.

TEGANI, Ulderico. L'arte et la civilità d'Italia nell'America Latina. In: Le Vie d'Italia e dell'America Latina, n. 2, fev. 1924.

TRENTO, Angelo. Os viajantes italianos na América Latina durante o período fascista: entre curiosidade e ideologia. In: Locus: revista de história, Juiz de Fora, v. 14, n. 2 , 2008.

VANGELISTA, Chiara. Uma revista italiana e a emigração no Brasil durante os primeiros anos do Fascismo: Le Vie d'Italia e dell'America Latina, 1924-1932. In: Veritas, v. 40, n. 159, 1995. 